\title{
SNAP participation and the health and health care utilisation of low-income adults and children
}

\author{
Daniel P Miller ${ }^{1, *}$ (1) and Taryn W Morrissey² \\ 'Boston University, School of Social Work, 264 Bay State Road, Boston, MA 02215, USA: ${ }^{2}$ American University, \\ School of Public Affairs, Washington, DC, USA
}

Submitted 24 March 2021: Final revision received 18 August 2021: Accepted 27 August 2021: First published online 6 September 2021

\begin{abstract}
Objective: This article examined whether participation in the Supplemental Nutrition Assistance Program (SNAP) produced changes to adult and child health and health care utilisation during a period of economic recession.

Design: Instrumental variables analysis relying on variation in state SNAP policies to isolate exogenous variation in household SNAP participation.

Setting: Nationally representative data on child and adult health from the 2008 to 2013 National Health Interview Survey.

Participants: Participants were 92237 adults and 45469 children who were either eligible for SNAP based on household income and state eligibility rules or were low income but not eligible for SNAP benefits.

Results: For adults, SNAP participation increased the probability of reporting very good or excellent health, and for both adults and children, reduced needing but having to go without dental care or eyeglasses. The size of these benefits was especially pronounced for children. However, SNAP participation increased the probability of needing but not being able to afford prescription medicine, and increased psychological distress for adults and behavioural problems for children under age 10 .

Conclusions: SNAP's benefits for adult health and improved access to dental and vision care for adults and children suggest benefits from the program's expansions during the current COVID-induced crisis. Predicted negative effects of SNAP participation suggest the need for attention to program and benefit structure to avoid harm and the need for continued research to explore the causal effects of program participation.
\end{abstract}

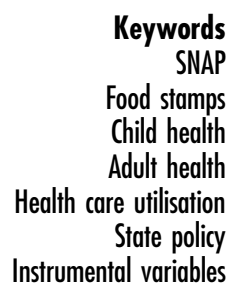

Food stamps

Child health

Adult health

State policy

Instrumental variables
Among the many hardships wrought by the COVID-19 pandemic has been a stunning increase in food insecurity in US households $^{(1,2)}$. As was true following previous crises ${ }^{(3)}$, participation in the Supplemental Nutrition Assistance Program (SNAP) has also spiked. Data from the United States Department of Agriculture (USDA) indicate a nearly $10 \%$ increase in the number of persons receiving SNAP benefits between March and April of 2020, followed by additional increases in successive months. In total, SNAP participation increased from roughly 37 million in March 2020 - a rate that had been more or less constant for the prior year - to a high of 43 million in June where it has remained relatively constant into $2021^{(4)}$.

The primary aim of SNAP is to reduce hunger and food insecurity. In this capacity, it is the cornerstone of the USDA's nutrition programs. However, there is growing recognition of additional benefits to participation. For example, in recent years, SNAP has occupied an important countercyclical role ${ }^{(5)}$, becoming a vital part of the social safety net ${ }^{(6)}$ and lifting more Americans out of poverty than any other means-tested program ${ }^{(7)}$. Outside of Medicaid, SNAP is currently the largest program for low-income Americans $^{(8)}$. In the midst of the current crises, all available evidence points to SNAP as an integral resource for supporting the nutritional and economic needs of the US population $^{(9)}$.

Building on studies that suggest that SNAP reduces food insecurity $^{(10,11)}$, researchers have begun to investigate some of the indirect or unintended, but still important, health benefits of participation ${ }^{(8)}$. SNAP may affect health by reducing food insecurity which is itself consistently related to poor nutrition and worse health ${ }^{(12-14)}$. In 
addition, previous research indicates that both SNAP participation and increases in benefit levels lead to increases in food expenditures and improved diet quality ${ }^{(15-17)}$. Thus, SNAP may benefit health by expanding household food budgets and allowing recipients to increase expenditures on healthier (and more expensive) foods. In turn, reductions to or the loss of SNAP benefits are associated with poorer health in families with young children despite increases in income ${ }^{(18)}$. In addition, because it can offset food costs, SNAP participation may free up resources that can be spent on health-promoting activities or directly on health care ${ }^{(19)}$. Having more resources may also reduce participants' stress and improve mental health ${ }^{(20-22)}$.

However, understanding the effects of SNAP participation is complicated by differential selection into the pro$\operatorname{gram}^{(23,24)}$. The tendency for the neediest households to participate in SNAP creates endogeneity bias, and so naïve comparisons of the health of recipients and nonrecipients typically point to worse health attached to participation, because participants tend to be worse off in both observed and unobserved ways. Only by using analyses of natural experiments and other methods to address endogeneity have researchers been able to convincingly estimate program effects ${ }^{(25)}$.

Perhaps for this reason, there is only a small literature examining SNAP participation and health or health care utilisation outcomes. The results of these studies are inconsistent ${ }^{(26)}$, with some finding SNAP receipt to be related to better self-reported health, fewer sick days, and better birth outcomes and lower mortality ${ }^{(27-29)}$, and others finding negative or mixed findings on birth outcomes ${ }^{(30)}$ and mental health ${ }^{(31)}$. Much of the remaining literature has focused only on obesity among adults and children, also with mixed findings ${ }^{(32-35)}$. Other studies estimate benefits to SNAP participation by taking advantage of the well-recognised tendency for SNAP households tend to exhaust their benefits by the end of the month ${ }^{(36)}$ and the practice in some states of disbursing SNAP benefits randomly across the calendar month. Findings from these studies are also inconsistent, with evidence for reduced emergency room visits for hypoglycaemia in low-income areas ${ }^{(37)}$ and reductions in visits for childhood injuries ${ }^{(38)}$, suggesting that the additional resources led to improved nutrition, health and reductions in parent stress. However, another study ${ }^{(39)}$ found no relationship between the timing of monthly SNAP receipt and hypoglycaemia.

Less research has examined whether SNAP participation affects non-emergency health care use. Although greater use of health care typically indicates poor health, the additional resources in the household provided by SNAP may allow families to purchase medical or preventive care they would otherwise delay or forego due to cost. Health care not typically covered by insurance, such as eyeglasses or dental care, may be particularly sensitive to household resources. The few studies on this topic suggest that SNAP participation and higher SNAP benefits result in improved self-reported health ${ }^{(27)}$, fewer doctor visits but more check-ups ${ }^{(27,40)}$ and reductions in the risk of medical hardship $^{(41)}$ and total medical expenditures ${ }^{(42)}$.

In sum, despite its importance as a safety net program, the effects of SNAP participation on health or on health care use for adults or children remain unclear. In this article, we use recent, nationally representative data from the National Health Interview Survey (NHIS) to estimate the effects of participation in the SNAP program on child and adult health and health care utilisation. Similar to other highquality studies of the SNAP program ${ }^{(25)}$, we use statistical methods - specifically, a quasi-experimental instrumental variables (IV) approach - designed to estimate plausibly causal effects of program participation. Importantly, we used data from 2008 to 2013 to examine SNAP participation, health and health care use during and just following the prior economic crisis, a period in which similar SNAP policy changes and high unemployment led to historic rates of SNAP enrollment ${ }^{(43)}$ to shed light on the current policy and economic context.

\section{Methods}

\section{Data and sample}

We used data from the 2008-2013 waves of the NHIS, a nationally representative cross-sectional survey, which was administered in person to between 29000 and 44552 households annually. Notably, this time period includes the Great Recession and early recovery but is also prior to the implementation of most of the Affordable Care Act's (ACA) expansions in insurance coverage, which occurred in 2014 and also affected health and health care use $^{(44,45)}$. In each family, an adult respondent to the NHIS provided information on a core set of topics for themselves and on behalf of every member of their family. From each family, a sample adult and a sample child (under 18, when present) were selected for additional surveys. Sample adults and children provided detailed information on health, health care utilisation and health behaviours. A knowledgeable adult in the family responded on behalf of the sample child ${ }^{(46)}$. We created our NHIS dataset using the Integrated Public use Microdata System website ${ }^{(47)}$.

We restricted our sample to respondents who were eligible to receive SNAP benefits. Federal rules limit eligibility for families without elderly or disabled members to $130 \%$ of the federal poverty line (FPL) or lower, but families in which all members receive benefits from Temporary Assistance for Needy Families or Supplemental Security Income are categorically eligible for SNAP. In addition, most states (43 out of 50 in 2013) extend categorical eligibility to higher income thresholds (between $130 \%$ and $200 \%$ FPL) to families where at least one member is eligible to receive benefits or services from a program funded by Temporary Assistance for Needy Families block grants ${ }^{(48)}$. Accordingly, we coded families as eligible if: (1) all members reported receiving 
Temporary Assistance for Needy Families or Supplemental Security Income benefits; (2) gross income for families without any elderly or disabled members was below the federal limit (130\% FPL) or the state-specific categorical eligibility limit, whichever was higher or (3) gross income was below $200 \%$ of the FPL for families with any elderly or disabled member, who face no gross income test but have a net income limit of $100 \%$ FPL. Net income is not measured in the NHIS, and $200 \%$ FPL was chosen as a conservative upper gross income limit for these families. The NHIS multiply imputes data on income where that information is missing $^{(46)}$. Because analysis of multiply imputed data is not possible with our analytic strategy, we omitted cases with imputed income.

Our analytic sample is comprised of 92237 adults and 45649 children for whom information was available in the core family survey, and subsets of 47089 sample adult survey respondents and 17705 sample children. For some analyses, our dependent variables are based on a subsample (e.g. children of a certain age), and we note these further restrictions wherever appropriate. State of residence and family income-to-poverty ratio were used to identify income eligibility for SNAP. State of residence was also used to merge in information on state SNAP policies and state-level controls (see description below). State of residence and income-to-poverty ratio are restricted variables in the NHIS, and therefore analyses were conducted at the National Center for Health Statistics in Hyattsville, MD, or a Census Research Data Center (in Cambridge, MA, and Suitland, MD).

\section{Adult and child bealth and bealth care measures}

We examined multiple health and health care utilisation outcomes. From the core survey, these included whether respondents or their children delayed seeking medical care or needed but did not get medical care because of cost in the past year and indicators for very good/excellent or fair/ poor health. We also included questions from the sample adult and sample child surveys: if the respondent or their child had a stomach problem or cold in the past 2 weeks; and, whether in the past year the respondent or child needed but could not afford dental care, eyeglasses, prescription medicines or mental health care, along with a measure of the number of different types of care (0-4) the respondent or child needed but could not afford. From the sample adult survey, we assessed the number of days in the past year the respondent reported being in bed for more than half of the day because of illness or injury; the respondent's score on the Kessler K6 measure (a widely used, short-form measure of psychological distress $)^{(49)}$; whether respondents had feelings that interfered with their lives in the past $30 \mathrm{~d}$; and, the number of days a respondent missed work in the past year because of illness or injury (asked only of those with a job in the past year, $n$ 22 579). Finally, from the sample child survey, we included measures for: adult reports of the number of school days missed because of illness or injury (asked for sample children ages 5-17, $n 13$ 662); children's scores on the Mental Health Indicator, a scale comprised of four items from the Child Behavior Checklist ${ }^{(36)}$ used to assess mental health among children aged 2-3 years old ( $n$ 2572; higher numbers indicating worse mental health); the Short Strengths and Difficulties Questionnaire, a five-item version of the longer Strengths and Difficulties Questionnaire ${ }^{(50)}$ used to determine emotional problems among children aged 4-17 (n 11 834; higher numbers indicating more problems); and an indicator for whether the child had difficulty with emotions, concentration or being able to get along with other people (scored $0=$ no to $3=$ yes, severe difficulties). Table 1 shows average scores by SNAP receipt for each variable.

\section{SNAP participation}

SNAP participation was coded as months of participation in the past calendar year and set equal to zero in households where no one reported receiving SNAP benefits. In additional analyses (available upon request), we replicated all analyses using a 0-1 indicator of household SNAP participation. These analyses yielded results that were qualitatively similar to those reported below.

\section{Analyses}

We used IV analyses to address the endogeneity of SNAP participation. IV analyses are a quasi-experimental approach that relies on the selection of a so-called instrument that is: (1) strongly related to an endogenous "treatment" of interest (SNAP participation); (2) only correlated with dependent variables (adult and child health) via its relationship with the treatment and (3) is as good as randomly assigned ${ }^{(51,52)}$. When these assumptions are met, IV can estimate a treatment effect of SNAP participation on child and health that is based only on the variation in participation prompted by changes to the instrument (in this study, more inclusive or less inclusive state rules regarding SNAP eligibility, enrollment and re-enrollment).

Although SNAP is subject to federal rules, states have some autonomy in program administration. Accordingly, previous studies have used natural variation in state-level SNAP policies regarding eligibility, recertification periods and benefit expansions as instruments to study the effects of SNAP participation on a variety of outcomes ${ }^{(27,32,53,54)}$. Consistent with this work, we selected nine policies as instruments from the USDA State SNAP Policy Database ${ }^{(55)}$, which records monthly state variation in policies. These included continuous measures of inflationadjusted spending on SNAP outreach and spending on SNAP outreach squared (both in 2015 constant dollars) and the proportion of SNAP households that were required to recertify eligibility within a 6-month period. We also selected (0-1) indicators for whether the state: had adopted 
Table 1 Key independent variable and dependent variable by SNAP receipt for the adult and child samples - NHIS 2008-2013

\begin{tabular}{|c|c|c|c|c|c|c|}
\hline \multirow{3}{*}{$\frac{\text { Variable }}{\text { SNAP receipt }}$} & \multicolumn{3}{|c|}{ Adult sample } & \multicolumn{3}{|c|}{ Child sample } \\
\hline & \multirow{2}{*}{$\frac{n}{92237}$} & \multicolumn{2}{|c|}{ Mean } & \multirow{2}{*}{$\frac{n}{45649}$} & \multicolumn{2}{|c|}{ Mean } \\
\hline & & $\begin{array}{c}0.401 \\
\text { SNAP recipients }\end{array}$ & Eligible non-recipients & & $\begin{array}{c}0.569 \\
\text { SNAP recipients }\end{array}$ & Eligible non- recipients \\
\hline Months of SNAP Receipt & 92237 & 9.889 & 0 & 45649 & 10.094 & 0 \\
\hline Delayed seeking medical care & 92237 & 0.191 & 0.171 & 45649 & 0.032 & 0.064 \\
\hline Needed but did not get care & 92237 & 0.179 & 0.142 & 45649 & 0.022 & 0.041 \\
\hline Fair or poor health & 92237 & 0.296 & 0.218 & 45649 & 0.041 & 0.028 \\
\hline Very good or excellent health & 92237 & 0.381 & 0.469 & 45649 & 0.726 & 0.759 \\
\hline Stomach problem in past 2 weeks & 47089 & 0.088 & 0.057 & 17705 & 0.072 & 0.051 \\
\hline Cold past 2 weeks & 47089 & 0.154 & 0.119 & 17705 & 0.180 & $0 \cdot 150$ \\
\hline Needed but could not afford & 47089 & & & & & \\
\hline Prescription medicine & & 0.216 & 0.134 & 17705 & 0.041 & 0.053 \\
\hline Dental care & & 0.306 & 0.217 & 17705 & 0.070 & 0.115 \\
\hline Eyeglasses & & 0.195 & $0 \cdot 130$ & 17705 & 0.031 & 0.045 \\
\hline Mental health care & & 0.065 & 0.040 & 17705 & 0.014 & $0.014^{*}$ \\
\hline \# Types of care respondent or child needed but could not afford & 47089 & 0.782 & 0.521 & 17705 & 0.156 & 0.228 \\
\hline \# Bed days in past year & 47089 & 11.388 & $6 \cdot 636$ & & & \\
\hline Kessler K6 score & 47089 & 4.728 & $3 \cdot 201$ & & & \\
\hline Feelings interfered with life & 47089 & 0.729 & 0.466 & & & \\
\hline \# Missed work days in last year & 22579 & $5 \cdot 251$ & 3.729 & & & \\
\hline \# Missed school days in last year & & & & 13662 & $4 \cdot 290$ & $3 \cdot 370$ \\
\hline Mental health indicator score & & & & 2572 & 1.430 & $1 \cdot 176$ \\
\hline Strengths and difficulties questionnaire score & & & & 11834 & $2 \cdot 107$ & 1.749 \\
\hline Difficulty with emotions, concentration, other people & & & & 15015 & 0.394 & 0.251 \\
\hline
\end{tabular}

${ }^{*}$ Comparison between SNAP recipients and eligible non-recipients is NS at $P<0.05$

All other comparisons are significant at $P<0.001$. 
a broad-based categorical eligibility policy; allowed SNAP applicants to exempt at least one vehicle from assets counted toward eligibility; required fingerprints or other biometric data to prove identity; used simplified reporting to allow recipients to maintain eligibility or expanded eligibility for SNAP to all non-citizen adults or non-citizen older adults. Many of these SNAP policies are likely correlated. Thus, as a final step, and following similar analyses from the $\mathrm{USDA}^{(56)}$, we created an average index after standardising (mean $=0, \mathrm{SD}=1)$ each of the nine policies $(\alpha=0 \cdot 70)$. We describe the full steps for creating this index in the Appendix. This index, which we use for all analyses, can be understood as measuring each state's overall approach to SNAP administration, and (as shown below) higher levels are associated with lower rates of SNAP participation.

In our analyses, we used two-stage least squares IV models. In the first stage, we predicted months of SNAP participation as a function of our state policy index and all other controls, generating what is referred to in the literature on IV analyses as a local average treatment effect ${ }^{(51,52)}$. Accordingly, our results are interpreted as estimates of the health or health care use effects of SNAP for NHIS respondents and their children living in households that changed their months of participation in response to changes in state policy $^{(51)}$. We included a number of controls to ensure that our analyses were robust to any violations of the assumptions for IV models. These were: health insurance coverage; family income to poverty ratio; respondent age and age-squared; education; labour force participation; race/ethnicity; citizenship status; gender; an indicator for family participation in the Special Supplemental Program for Women, Infants and Children; marital status; household size, the presence of older adults or persons with a disability in the respondent's family; home ownership and the month and year of survey. In our analyses of child health outcomes, we modified these controls by including indicators for the maximum education level among adults in the family and the presence of any employed adult in the household, and omitted indicators for marital status (which do not apply to children). For the few control variables with missing data, we coded missing responses $(<1 \%$ for variables such as labour force participation, education, citizenship and marital status) as 'unknown' and included them in the analyses. Last, we controlled for a number of state-level factors including annual average per capita income in the previous calendar year, annual average state unemployment rate in the previous calendar year and 2 years earlier and the food insecurity rate in the calendar year before the survey. Some previous studies have included state-fixed effects to ensure the conditional independence of their instruments. However, for the period of our study, the majority of variability in state SNAP policies occurs between states: state-fixed effects explained nearly $96 \%$ of the variation in our state SNAP policy index. Thus, the use of state-fixed effects was not possible with our instrumental variables design. In all analyses, we clustered standard errors at the state level.

\section{Results}

The first two rows of Table 1 show the rate of SNAP receipt in the adult and child samples and the average months of SNAP receipt in the past calendar year. Among adults, just over $40 \%$ lived in a household that received SNAP benefits in the previous calendar year, and the average recipient household had about 9.9 months of SNAP receipt. A greater proportion of children lived in a household that received SNAP (56.9\%), but months of receipt were comparable to that of adults ( $10 \cdot 1$ months).

Table 1 also shows unadjusted mean levels of the dependent variables for children and adults living in SNAP recipient and eligible non-recipient households. In nearly every case, there were significant $(P<0.001)$ differences between SNAP recipients and eligible nonrecipients. Among adults, these differences reflect the expected negative selection into SNAP participation described in previous research. For example, adult recipients had an average of 0.782 types of care that they needed but could not afford compared to an average 0.521 for eligible non-recipients. Adults in households that received SNAP were also more likely to have delayed seeking care $(19 \cdot 1 \% v \cdot 17 \cdot 1 \%)$, were more likely to be in fair or poor health (29.6\% v. 21.8\%) and spent significantly more days in bed (11.388v. 6.636) and out of work (5.251 v. 3.729). Though children living in SNAP households differed from eligible non-recipient children on every outcome except needing but not being able to afford mental health care, they did not fare worse universally. In fact - and likely reflective of their higher rates of insurance coverage (see Table 2) - SNAP recipient children were less likely to have delayed seeking medical care, to report needing but not getting care, or to report needing but not being able to afford prescription drugs, dental care or eyeglasses. Like SNAP recipient adults, however, they were more apt to be in fair or poor health $(4.1 \% v .2 \cdot 8 \%)$ and to have stomach problems $(7 \cdot 2 \% v \cdot 5 \cdot 1 \%)$ or a cold $(18 \% v .15 \%)$ in the past 2 weeks than non-recipients. SNAP recipient children also fared worse for each of the three indicators of social or behavioural problems.

Table 2 presents descriptive statistics separately for adults and children and by SNAP receipt for all other variables. For the most part, the descriptive results paint a picture of children and adults in SNAP recipient households as worse off than eligible non-recipient households, though there are a couple of notable exceptions. For example, as mentioned above, nearly $95 \%$ of SNAP recipient children had health insurance coverage, compared to only $82 \%$ of non-recipients. Rates of insurance coverage were also marginally higher among adult SNAP recipients as was household income-to-needs ratio. With respect to our state-level controls, SNAP recipients and non-recipients lived in states with statistically similar levels of per capita income, but recipients lived in states with higher levels of unemployment and food insecurity. 
Table 2 Descriptive statistics by SNAP Receipt - NHIS* 2008-2013

\begin{tabular}{|c|c|c|c|c|}
\hline & \multicolumn{2}{|c|}{ Adult sample ( $n 92337$ ) } & \multicolumn{2}{|c|}{ Child sample ( $n 45$ 649) } \\
\hline & SNAP recipients & Eligible non- recipients & SNAP recipients & Eligible non- recipients \\
\hline Health insurance coverage & 0.680 & 0.656 & 0.949 & 0.818 \\
\hline Household income-to-needs ratio & $1 \cdot 152$ & $1 \cdot 105$ & 0.918 & 1.048 \\
\hline Age & 41.444 & $47 \cdot 146$ & $7 \cdot 826$ & $8 \cdot 612$ \\
\hline \multicolumn{5}{|l|}{ Education } \\
\hline Less than high school & 0.350 & 0.313 & 0.257 & 0.230 \\
\hline High school degree & 0.325 & 0.309 & 0.304 & 0.287 \\
\hline Some college & 0.184 & 0.189 & 0.234 & 0.208 \\
\hline Associate's degree & 0.077 & 0.072 & 0.116 & 0.114 \\
\hline Bachelor's degree & 0.044 & 0.082 & 0.053 & 0.096 \\
\hline Graduate school & 0.011 & 0.026 & 0.014 & 0.034 \\
\hline Unknown & 0.008 & 0.010 & 0.022 & 0.032 \\
\hline \multicolumn{5}{|l|}{ Labor force status ${ }^{\star}$} \\
\hline Employed & 0.399 & 0.436 & 0.716 & 0.871 \\
\hline Unemployed & 0.135 & 0.082 & & \\
\hline Not in labour force & 0.465 & 0.482 & & \\
\hline Unknown & 0.001 & 0.001 & & \\
\hline \multicolumn{5}{|l|}{ Race and ethnicity } \\
\hline White, not Hispanic & 0.379 & 0.442 & 0.266 & 0.274 \\
\hline Black, not Hispanic & 0.276 & 0.154 & 0.267 & 0.145 \\
\hline Asian, not Hispanic & 0.034 & 0.072 & 0.024 & 0.055 \\
\hline Hispanic, any race & 0.291 & 0.321 & 0.418 & 0.512 \\
\hline Other & 0.019 & 0.011 & 0.024 & 0.014 \\
\hline \multicolumn{5}{|l|}{ Citizen } \\
\hline No or unknown & 0.142 & 0.215 & 0.030 & 0.085 \\
\hline Yes & 0.858 & 0.785 & 0.970 & 0.915 \\
\hline Male & 0.369 & 0.460 & 0.509 & $0.514 \dagger$ \\
\hline Receipt of WIC & 0.068 & 0.018 & 0.203 & 0.125 \\
\hline \multicolumn{5}{|l|}{ Marital status* } \\
\hline Married & 0.321 & 0.416 & & \\
\hline Not currently married & 0.251 & 0.247 & & \\
\hline Cohabiting & 0.127 & 0.059 & & \\
\hline Never married or unknown & 0.301 & 0.277 & & \\
\hline Family size & 3.515 & $2 \cdot 857$ & $4 \cdot 817$ & $4.795 t$ \\
\hline Any older adult in household & 0.241 & 0.407 & 0.065 & 0.120 \\
\hline Any person with a disability in household & 0.288 & $0 \cdot 160$ & 0.173 & 0.122 \\
\hline \multicolumn{5}{|l|}{ Home ownership } \\
\hline Own/mortgage & 0.305 & 0.473 & 0.250 & 0.438 \\
\hline Rent & 0.658 & 0.484 & 0.718 & 0.536 \\
\hline Other & 0.036 & 0.043 & 0.032 & 0.026 \\
\hline \multicolumn{5}{|l|}{ State-level variables } \\
\hline Per capita income $(\$ 2015)$ & 40974.7 & $41002 \cdot 1 \dagger$ & $40900 \cdot 5$ & $40995.5 t$ \\
\hline Unemployment & 8.391 & $8 \cdot 142$ & 8.415 & 8.096 \\
\hline Lagged unemployment & $8 \cdot 207$ & 7.586 & $8 \cdot 222$ & 7.466 \\
\hline Food insecurity & 0.144 & 0.140 & 0.146 & 0.141 \\
\hline State SNAP policy index & 0.350 & 0.500 & 0.462 & 0.598 \\
\hline
\end{tabular}

NHIS, National Health Interview Survey; SNAP, Supplemental Nutrition Assistance Program; WIC, Special Supplemental Program for Women, Infants and Children. ${ }^{*}$ For the child sample, education refers to the highest adult education in the household. Labour force status indicates whether any household adult is employed. Marital status is not included as a control for analyses with the child sample.

†Comparison between SNAP recipients and eligible non-recipients is NS at $P<0.05$. All other comparisons are significant at $P<0.001$.

Table 3 presents the IV results for adult health. For the sake of parsimony, the table presents only coefficients for the months of SNAP participation variable from the second stage regression; full results are available from the authors upon request. Coefficients are interpreted as the linear change in health or health care utilisation related to each additional month of SNAP participation. In addition, the table shows the $F$-statistics from the first stage regressions, which quantify the strength of the SNAP state policy index on months of SNAP participation. In the adult outcome models, $F$-statistics suggest that the state SNAP policy index was strongly predictive of months of SNAP participation.
The values of this statistic, ranging between $50 \cdot 109$ and 337.652 , far exceed the traditional critical threshold of 10 for strong instruments ${ }^{(44)}$.

Months of SNAP participation were significantly related to a number of adult health outcomes. Among adults whose months of SNAP participation changed in response to changes in state policies, each additional month of SNAP participation produced a significant and large increase of 1.7 percentage points $(0.017)$ in the probability of very good or excellent health. This is equivalent to a nearly $4.5 \%$ increase in the probability of very good or excellent health relative to the average for adult SNAP 
Table 3 SNAP participation and adult health, NHIS 2008-2013

\begin{tabular}{lcccc}
\hline & $n$ & SNAP months participation coefficient & $95 \%$ Cl & First stage F-statistic \\
\hline Variable & & & \\
Delayed seeking medical care & 92337 & 0.001 & $-0.006,0.008$ & 282.917 \\
Needed but did not Get Care & 92337 & 0.000 & $-0.006,0.006$ & $-0.008,0.007$ \\
Fair or poor health & 92337 & 0.000 & $0.007,0.028$ \\
Very good or excellent health & 92337 & $0.017^{\star \star}$ & $-0.011,0.000$ & $337 \cdot 652$ \\
\hline Stomach problem in past 2 weeks & 47089 & $-0.006+$ & $-0.009,0.007$ \\
Cold past 2 weeks & 47089 & -0.001 & $0.000,0.016$ \\
Needed but could not afford & 47089 & $0.008^{\star}$ & $-0.048,-0.027$ \\
Prescription medicine & 47089 & $-0.038^{\star \star *}$ & $-0.034,-0.017$ \\
Dental care & 47089 & $-0.026^{\star \star *}$ & $-0.006,0.003$ \\
Eyeglasses & 47089 & -0.001 & $-0.079,-0.033$ \\
Mental health care & 47089 & $-0.056^{\star \star *}$ & $-1.407,0.199$ \\
Needed any type of care but could not afford & 47089 & -0.604 & $0.002,0.217$ \\
\# Bed days in past year & 47089 & $0.109^{\star}$ & $-0.029,0.013$ \\
Kessler K6 score & 47089 & -0.008 & $-2.313,0.245$ \\
Feelings interfered with life & 22579 & -1.034 & $50 \cdot 109$ \\
\hline \# Missed work days in last year & & & \\
\hline
\end{tabular}

NHIS, National Health Interview Survey; SNAP, Supplemental Nutrition Assistance Program.

${ }^{\star} P<0.05$.

${ }^{\star *} P<0.01$.

${ }^{\star * \star} P<0.001$

recipients. Each additional month of SNAP participation also produced significant decreases in the probability of needing but not being able to afford dental care $(-3.8$ percentage points; a decrease of $12.4 \%$ relative to the average adult SNAP recipient) or eyeglasses $(-2.6$ percentage points; $13.3 \%$ decline), and a decrease of 0.056 in the number of types of care they needed but could not afford ( $-7.2 \%$ decline). Each additional month of SNAP participation was also related to significant increases in the probability that adults needed but could not afford prescription medicine ( 0.8 percentage points) and in the Kessler K6 score for psychological distress $(0.109$ points). However, these effects were relatively small, tantamount to increases of $3.7 \%$ and $2.3 \%$ compared to the average levels of unmet prescription need and Kessler scores among SNAP recipients.

Results for child health are presented in Table 4. Unlike for adults, SNAP participation did not produce significant increases in the probability of very good or excellent health among children. Each additional month of participation did, however, generate large decreases in the probability of needing but not being able to afford dental care of 3.9 percentage points (a decrease of $55.7 \%$ compared to the average SNAP recipient child), or eyeglasses $(-1.8$ percentage points; $58 \%$ decline), and in the number of types of care children of respondents needed but could not afford $(-0.064 ; 57.7 \%)$. Each additional month of SNAP participation also significantly increased Short Strengths and Difficulties Questionnaire scores by $0.246(11.7 \%)$, indicating more emotional or behavioural problems. For all dependent variables except Mental Health Indicator Score (where analyses were based on a small subsample of eligible children), the $F$-statistic indicated a strong relationship between the state SNAP policy index and SNAP participation.

\section{Discussion}

Given its major role in the US social welfare system, understanding the full effects of SNAP participation is an important goal. Evidence about the program's impacts is essential for developing a more complete understanding of the social safety net and is especially significant in light of recent legislative proposals that would result in major changes to SNAP. In this article, we used a rigorous analysis of nationally representative data to examine whether participation in the SNAP program was related to the health and health care utilisation of low-income adults and children.

Building on a conflicting and small body of existing research, we found that each additional month of SNAP participation increased the probability of very good or excellent health for adults. For both children and adults, each additional month of SNAP participation reduced the probability of needing but having to go without dental care or eyeglasses and decreases the number of types of care that respondents and their children needed but was unable to afford. When compared to the mean rate of these problems among SNAP recipient adults in our sample, these effects were sizeable, equivalent to between a $7 \%$ and $13 \%$ decrease from the average. For children, the relative size of these effects was even bigger, amounting to more than a $50 \%$ decrease for each outcome and likely reflective of the low rates of medical hardships among children in our sample. In contrast, we found that additional months of 
Table 4 SNAP participation and child health, NHIS 2008-2013

\begin{tabular}{|c|c|c|c|c|}
\hline & $n$ & $\begin{array}{l}\text { SNAP months participation } \\
\text { coefficient }\end{array}$ & $95 \% \mathrm{Cl}$ & First stage $F$-statistic \\
\hline \multicolumn{5}{|l|}{ Variable } \\
\hline Delayed seeking medical care & 45649 & -0.007 & $-0.017,0.004$ & $33 \cdot 643$ \\
\hline Needed but did not get care & 45649 & -0.007 & $-0.016,0.002$ & \\
\hline Fair or poor health & 45649 & 0.000 & $-0.009,0.010$ & \\
\hline Very good or excellent health & 45649 & 0.012 & $-0.016,0.040$ & \\
\hline Stomach problem in past 2 weeks & 17705 & -0.012 & $-0.028,0.005$ & $35 \cdot 921$ \\
\hline Cold past 2 weeks & 17705 & -0.016 & $-0.040,0.009$ & \\
\hline \multicolumn{5}{|l|}{ Needed but could not afford } \\
\hline Prescription medicine & 17705 & -0.005 & $-0.019,0.009$ & \\
\hline Dental care & 17705 & $-0.039^{* \star *}$ & $-0.061,-0.017$ & \\
\hline Eyeglasses & 17705 & $-0.018^{* *}$ & $-0.032,-0.005$ & \\
\hline Mental health care & 17705 & -0.001 & $-0.009,0.007$ & \\
\hline Needed any type of care but could not afford & 17705 & $-0.064^{\star *}$ & $-0.103,-0.033$ & \\
\hline \# Missed school days in last year & 13662 & -0.286 & $-0 \cdot 832,0.260$ & $35 \cdot 388$ \\
\hline MHI score & 2572 & -0.013 & $-0.413,0.387$ & $2 \cdot 093$ \\
\hline SDQ score & 11834 & $0 \cdot 246^{\star \star}$ & $0.086,0.407$ & $26 \cdot 704$ \\
\hline Difficulty with emotions, concentration, other people & 15015 & 0.036 & $-0.007,0.080$ & 34.967 \\
\hline
\end{tabular}

MHI, Mental Health Indicator; NHIS, National Health Interview Survey; SDQ, Strengths and Difficulties Questionnaire; SNAP, Supplemental Nutrition Assistance Program. ${ }^{* *} P<0.01$.

${ }^{\star * \star} P<0.001$.

SNAP receipt also increased the probability of needing but not being able to afford prescription medicines and psychological distress for adults and emotional or behavioural problems (Short Strengths and Difficulties Questionnaire scores) for children under age 10. When compared to the relative benefits of additional months of SNAP receipt, these negative effects were smaller but nonetheless practically important, and we discuss these results in greater depth below.

Consistent with some previous research ${ }^{(27,28)}$, our results point mostly to beneficial impacts of SNAP participation on health and health care utilisation. Our finding of significant increases in the probability of very good or excellent health for adults for each additional month of participation in SNAP is noteworthy. Results from our model suggest that a full year of SNAP participation would increase the probability of very good or excellent health by 20.4 percentage points, a more than $50 \%$ increase off the mean level of $0 \cdot 381$ for SNAP recipients. This finding is especially meaningful in the light of recent changes to the SNAP program, specifically the temporary expansion of benefits during the pandemic and economic crisis, flexible Pandemic EBT and additional federal funds to cover state administrative costs, as included in the American Rescue Package ${ }^{(57)}$. These changes are likely to encourage participation and for longer lengths of time, and our study indicates that health benefits will follow. How SNAP affects adults' and children's health care use following the ACA's full implementation - and further expansion under the American Rescue Plan ${ }^{(58)}-$ remains an important issue for further research.

Unlike for adults, months of SNAP participation were not related to adult reports of children's health. This may be a result of a 'ceiling effect', such that more than threequarters of eligible non-recipients and over $72 \%$ of children in SNAP households were in very good or excellent health; thus, marginal increases in months of SNAP participation may have not been sufficient to improve health in the somewhat infrequent cases where children were in poorer health.

For both children and adults, months of SNAP participation resulted in lower rates of needing but not being able to afford dental care or eyeglasses. For most insurance plans, vision and dental benefits for adults are supplemental benefits, and thus, low-income adults are likely to delay dental and vision health care needs. However, even before the ACA required paediatric dental and vision coverage as essential health benefits, most Medicaid programs and private health insurance plans provided these benefits to children ${ }^{(59,60)}$. But, even with coverage, identifying providers who accept Medicaid may be difficult. Thus, among adults and children, extra household resources appear to help families use health care that they would have otherwise delayed or foregone. Among children, addressing oral health and vision needs is particularly important, given the effects of dental and vision problems on school attendance and academic outcomes ${ }^{(61-63)}$.

Not all predicted effects were beneficial. Additional months of SNAP participation generated higher adult K6 scores and child Short Strengths and Difficulties Questionnaire scores, indicating poorer mental and behavioural health accompanying additional months of SNAP participation. Because SNAP participation ought to reduce stress, increase food and non-food spending and reduce food insecurity, the reason behind these negative predicted 
effects on mental or behavioural health is not immediately clear, but may reflect increased stigma attached to program participation. Alternatively, despite our use of IV models to generate a casual estimate of SNAP participation, results may yet reflect residual confounding. For example, Table 1 shows that for both children and adults, incomeeligible non-recipients were significantly more likely than SNAP recipients to be non-citizens or to have unknown citizenship. It is well-known that recent immigrants have better health than non-immigrants of similar socioeconomic status $^{(64)}$, and while our analyses controlled for citizenship status, the potential over-representation of recent and healthier immigrants in our comparison group may be responsible for this result. Or, it is possible that these results reflect persistent poverty, which is not captured by the point-in-time estimates of income in the NHIS, and which is more strongly associated with children's externalising problems than intermittent poverty ${ }^{(65)}$. However, this does not explain our multiple findings pointing to better health among SNAP participants. Whatever their cause, increases in psychological distress and behaviour problems are problematic, and additional research should explore whether these findings persist in other samples, especially ones collected during the COVID-19 pandemic. It may be necessary to explore targeted programs to help remediate these (or other) negative effects for SNAP recipients.

In addition, each additional month of SNAP participation for adults produced a small but significant increase of 0.8 percentage points in the probability of needing but not being able to afford prescription medicine. It may be that the increases in mental or behavioural health problems described above led to an increased need for medication. Alternatively, it is possible that greater access to dental or vision care afforded by SNAP participation resulted in additional diagnoses and need for medical care that was difficult to fund for SNAP recipients. The magnitude of this relationship was not large enough to offset the predicted reduction in the number of types of care that adults needed but could not afford, but it is nonetheless deserving of additional scrutiny.

Our study has several limitations. IV models are a quasiexperimental approach that (when assumptions are met) produce a particular causal estimate - a LATE ${ }^{(51,52)}$ - which here means that our results must be interpreted as the effects of an additional month of SNAP participation among those who changed their participation in response to the variability in state policies. Effects of participation for this group may be substantially different, say, than for those in extremely low-income households, for whom SNAP benefits make up an outsized share of family resources and for whom variability in SNAP policy may have little impact on their decision to participate in the program. For example, the effects of social stigma surrounding public program participation ${ }^{(66)}$ may be particularly strong among those who varied their participation as a consequence of state policies, affecting their mental and behavioural health more so than among other groups of SNAP participants. Indeed, studies of universal school meal programs find increased participation and improvements in a range of benefits, potentially via reductions in social stigma ${ }^{(67,68)}$. Further, because most policy variation occurred between states, we are unable to include state-fixed effects in our analyses. Related to our analytic approach, while the use of SNAP policy index is justified on methodological grounds ${ }^{(56)}$, its use in an IV framework precludes us from identifying which of the particular policies were responsible for changing months of participation. Additional research should explore whether the nature and magnitude of effects reported here are comparable when using other methods to develop causal estimates of participation.

Second, the measures of health and health care utilisation in the NHIS are based on respondent report and thus subject to bias. Likewise, it is well-known that survey respondents misreport participation in SNAP and other public programs, creating some concern about bias in our measure of participation ${ }^{(24)}$. It will be instructive to assess whether conclusions from this study hold up using objective measures of health, health care utilisation and SNAP participation that are based on administrative data sources or are collected by clinicians. Nonetheless, we believe that the many benefits of the NHIS (national representativeness, recency, large sample size) outweigh the limitations of self-reported data. Also, while we were careful to match state SNAP policies to the reference period for SNAP participation (the calendar year before the survey), which in turn mostly pre-date the reference periods for our health outcomes, the structure of the NHIS does not make it possible to definitively discern the temporal ordering of the key variables for our study. An ideal dataset for our analyses would be longitudinal in nature and would utilise administrative data to track specific periods of SNAP participation as well as health outcomes. We are not aware of any such data source that simultaneously achieves the breadth and representativeness of the NHIS, however.

Third, though our analyses were distinguished by the careful use of state- and time-specific rules for SNAP eligibility and the use of quasi-experimental IV analyses to generate plausibly causal estimates of SNAP participation, we cannot fully rule out the potential for bias in our estimates. For example, because families must have persistently low incomes to remain eligible for SNAP, our results may be biased because of confounding by indication, wherein long-term spells of low income are associated with both SNAP participation and health outcomes ${ }^{(65)}$. Relatedly, the cross-sectional NHIS data prevent the exploration of how within-household income dynamics affect SNAP benefit levels and participation, which can lead to changes in health ${ }^{(18)}$. In addition, our focus is on the effects of SNAP participation, but low-income families are often eligible for and participate in multiple safety net programs such as Medicaid and the Earned Income Tax Credit that also affect health and health care use $\mathrm{e}^{(44,45,69,70)}$. However, 
we argue that our use of multiple controls, including household income and health insurance coverage should help to account for the effects of participation in these programs. Finally, our data were collected during and in the aftermath of the Great Recession, the most recent prior economic downturn but one quite different than today's pandemicinduced crisis. Our results can shed light on the role that SNAP plays in promoting health and health care use during times of elevated participation and benefit levels, but future research should also use recent data to examine SNAP's role in the current policy context and economic crisis.

Our findings indicate that SNAP has some positive impacts on the health and health care utilisation of child and adult participants beyond its intended goal of nutrition assistance, which may be useful in predicting the consequences of expansions in SNAP participation and benefits in response to the dramatic increase in food insecurity and need during the COVID-induced crisis ${ }^{(71)}$. While the majority of our findings suggest benefits for health, our analyses also find some negative effects on mental and behavioural health. Additional research that helps clarify the mechanisms via which participation affects the health of lowincome children and adults may be useful for building upon existing food and nutrition assistance programs to help maximise benefits to health and other outcomes while minimising or eliminating any resulting costs.

\section{Acknowledgements}

Acknowledgements: The findings and conclusions in this article are those of the authors and do not necessarily represent the views of the Research Data Center, the National Centre for Health Statistics or the Centers for Disease Control and Prevention. Financial support: This work was supported with a grant from the University of Kentucky Center for Poverty Research through funding by the U.S. Department of Agriculture, Economic Research Service and Food and Nutrition Service [number 3048110944-16-016]. The opinions and conclusions expressed herein are solely those of the author(s) and should not be construed as representing the opinions or policies of the UKCPR or any agency of the Federal Government. The University of Kentucky Center for Poverty Research had no role in the design, analysis or writing of this article. Conflicts of interest: There are no conflicts of interest. Authorship: Both authors contributed to the research by formulating the research questions, designing the study, preparing the data, and writing the article. Dr. D.P.M. led in the analysis of data. Ethics of human subject participation: Not applicable.

\section{Supplementary material}

For supplementary material accompanying this paper visit https://doi.org/10.1017/S1368980021003815

\section{References}

1. Schanzenbach DW \& Pitts A (2020) How Much Has Food Insecurity Risen? Evidence from the Census Household Pulse Survey. Evanston, IL: Institute for Policy Research, Northwestern University.

2. Wolfson JA \& Leung CW (2020) Food insecurity and COVID19: disparities in early effects for US adults. Nutrients 12, 1648.

3. Rosenbaum D \& Keith-Jennings B (2019) SNAP Caseload and Spending Declines Have Accelerated in Recent Years. Washington, DC: Center on Budget and Policy Priorities.

4. USDA (2020) Supplemental Nutrition Assistance Program (Data as of December 11, 2020). Washington, DC: U.S. Department of Agriculture.

5. Ziliak JP (2015) Why are so many Americans on food stamps? The role of the economy, policy, and demographics. In SNAP Matters: How Food Stamps Affect Health and Well-Being, pp. 18-48 [JS Bartfeld, CG Gundersen, T Smeeding et al., editors]. Palo Alto, CA: Stanford University Press.

6. Sherman A \& Trisi D (2015) Safety Net More Effective Against Poverty Than Previously Thought. Washington, DC: Center on Budget and Policy Priorities.

7. Tiehen L, Jolliffe D \& Smeeding T (2015) The effect of SNAP on poverty. In SNAP Matters: How Food Stamps Affect Health and Well-Being, pp. 49-73 [JS Bartfeld, CG Gundersen, T Smeeding et al., editors]. Palo Alto, CA: Stanford University Press.

8. Falk G, Lynch KE \& Tollestrup J (2018) Federal Spending on Benefits and Services for People with Low Income: In Brief. Washington, DC: Center on Budget and Policy Priorities.

9. Center on Budget and Policy Priorities (2021) States are Using Much-Needed Temporary Flexibility in SNAP to Respond to COVID-19 Challenges. Washington, DC: Center on Budget and Policy Priorities.

10. Malbi J, Ohls J, Dagnoset L et al. (2013) Measuring the Effect of Supplemental Nutrition Assistance Participation on Food Insecurity. Washington, DC: U.S. Department of Agriculture.

11. Ratcliffe C, McKernan SM \& Zhang S (2011) How much does the supplemental nutrition assistance program reduce food insecurity? Am J Agric Econ 93, 1082-1098.

12. Bhattacharya J, Currie J \& Haider S (2004) Poverty, food insecurity, and nutritional outcomes in children and adults. $J$ Health Econ 23, 839-862.

13. Gundersen CG \& Ziliak JP (2015) Food insecurity and health outcomes. Health Aff 34, 1830-1839.

14. Thomas MMC, Miller DP \& Morrissey TW (2019) Food insecurity and child health. Pediatrics 144, e20190397.

15. Bruich GA (2014) The Effect of SNAP Benefits on Expenditures: New Evidence from Scanner Data and the November 2013 Benefit Cuts. Cambridge, MA: Harvard University Working Paper.

16. Beatty TKM \& Tuttle CJ (2015) Expenditure response to increases in in-kind transfers: evidence from the supplemental nutrition assistance program. Am J Agric Econ 97, 390-404.

17. Hoynes HW \& Schanzenbach DW (2009) Consumption responses to in-kind transfers: evidence from the introduction of the food stamp program. Am Econ J Appl Econ 1, 109-139.

18. de Cuba SE, Chilton M, Bovell-Ammon A et al. (2019) Loss of SNAP is associated with food insecurity and poor health in working families with young children. Health Aff $\mathbf{3 8}$, $765-773$

19. Morrissey TW \& Miller DP (2020) Supplemental nutrition assistance program participation improves children's health care use: an analysis of the American recovery and reinvestment act's natural experiment. Acad Pediatr 20, 863-870. 
20. Gennetian LA \& Shafir E (2015) The persistence of poverty in the context of financial instability: a behavioral perspective. J Policy Anal Manag 34, 904-936.

21. Blair C \& Raver CC (2016) Poverty, stress, and brain development: new directions for prevention and intervention. Acad Pediatr 16, S30-S36.

22. Ohrnberger J, Anselmi L, Fichera E et al. (2020) The effect of cash transfers on mental health: opening the black box - a study from South Africa. Soc Sci Med 260, 1-13.

23. Bitler MP (2015) The health and nutrition effects of SNAP: selection into the program and a review of the literature on its effects. In SNAP Matters: How Food Stamps Affect Health and Well-Being, pp. 134-160 [JS Bartfeld, CG Gundersen, $\mathrm{T}$ Smeeding et al., editors]. Stanford, CA: Stanford University Press.

24. Kreider B, Pepper JV, Gundersen CG et al. (2012) Identifying the effects of SNAP (food stamps) on child health outcomes when participation is endogenous and misreported. J Am Stat Assoc 107, 958-975.

25. Gregory CA, Rabbitt MP \& Ribar DC (2015) The supplemental nutrition assistance program and food insecurity. In SNAP Matters: How Food Stamps Affect Health and Well-Being, pp. 74-106 [JS Bartfeld, CG Gundersen, T Smeeding et al., editors]. Stanford, CA: Stanford University Press.

26. Meyerhoefer CD \& Yang M (2011) The relationship between food assistance and health: a review of the literature and empirical strategies for identifying program effects. $A p p l$ Econ Perspect Policy 33, 304-344.

27. Gregory CA \& Deb P (2015) Does SNAP improve your health? Food Policy 50, 11-19.

28. Almond D, Hoynes HW \& Schanzenbach DW (2011) Inside the war on poverty: the impact of food stamps on birth outcomes. Rev Econ Stat 93, 387-403.

29. Heflin CM, Ingram SJ \& Ziliak JP (2019) The effect of the supplemental nutrition assistance program on mortality. Health Aff 38, 1807-1815.

30. Currie J \& Moretti E (2008) Did the introduction of food stamps affect birth outcomes in California? In Making Americans Healthier: Social and Economic Policy as Health Policy, pp. 122-142 [R Schoeni, J House, C Kaplan et al., editors]. New York, NY: Russell Sage.

31. Heflin CM \& Ziliak JP (2008) Food insufficiency, food stamp participation, and mental health. Soc Sci Q 89, 706.

32. Meyerhoefer CD \& Pylypchuk Y (2008) Does participation in the food stamp program increase the prevalence of obesity and health care spending? Am J Agric Econ 90, 287-305.

33. Schmeiser MD (2012) The impact of long-term participation in the supplemental nutrition assistance program on child obesity. Health Econ 21, 386-404.

34. Gibson D (2006) Long-term food stamp program participation is positively related to simultaneous overweight in young daughters and obesity in mothers. $J$ Nutr 136, 1081-1085.

35. Baum CL (2011) The effects of food stamps on obesity. South Econ J 77, 623-651.

36. Castner L \& Henke J (2011) Benefit Redemption Patterns in the Supplemental Nutrition Assistance Program. Washington, DC: U.S. Department of Agriculture.

37. Basu S, Berkowitz SA \& Seligman HK (2017) The monthly cycle of hypoglycemia. Med Care 55, 639-645.

38. Heflin CM, Arteaga I, Ndashimye JF et al. (2020) Childhood injuries and food stamp benefits: an examination of administrative data in one US state. BMC Pediatr 20, 297.

39. Heflin CM, Hodges L \& Mueser P (2017) Supplemental nutrition assistance program benefits and emergency room visits for hypoglycemia. Public Health Nutr 20, 1314-1321.

40. Bronchetti E, Christensen G \& Hoynes H (2019) Local food prices, SNAP purchasing power, and child health. $J$ Health Econ 68, 102231.
41. Shaefer HL \& Gutierrez IA (2013) The supplemental nutrition assistance program and material hardships among lowincome households with children. Soc Serv Rev 87, 753-779.

42. Berkowitz SA, Seligman HK, Rigdon J et al. (2017) Supplemental nutrition assistance program (SNAP) participation and health care expenditures among low-income adults. JAMA Intern Med 177, 1642-1649.

43. Ganong P \& Liebman JB (2018) The decline, rebound, and further rise in SNAP enrollment: disentangling business cycle fluctuations and policy changes. Am Econ J Econ Policy 10, 153-176.

44. Soni A, Wherry LR \& Simon KI (2020) How have ACA insurance expansions affected health outcomes? Findings from the literature. Health Aff 39, 371-378.

45. Simon K, Soni A \& Cawley J (2017) The impact of health insurance on preventive care and health behaviors: evidence from the first 2 years of the ACA Medicaid expansions. $J$ Policy Anal Manag 36, 390-417.

46. National Center for Health Statistics (2021) National Health Interview Survey. https://www.cdc.gov/nchs/nhis/index. htm (accessed March 2021).

47. Ruggles S, Flood S, Goeken R et al. (2018) IPUMS USA: Version 8.0 (NHIS). https://doi.org/10.18128/D010. V8.0 (accessed July 2016).

48. Laird E \& Trippe C (2014) Programs Conferring Categorical Eligibility for SNAP: State Policies and the Number and Characteristics of Households Affected. Washington, DC: Mathematica.

49. Kessler RC, Andrews G, Colpe LJ et al. (2002) Short screening scales to monitor population prevalence's and trends in non-specific psychological distress. Psychol Methods 32, 959-976

50. Bourdon KH, Goodman R, Rae DS et al. (2005) The strengths and difficulties questionnaire: US normative data and psychometric properties. J Am Acad Child Adolesc Psychiatry 44, 557-564.

51. Angrist JD \& Pischke J-S (2009) Mostly Harmless Econometrics. Princeton, NJ: Princeton University Press.

52. Angrist JD \& Pischke J-S (2014) Mastering Metrics: The Path from Cause to Effect. Princeton, NJ: Princeton University Press.

53. Gregory CA, Ver Ploeg M, Andrews M et al. (2013) Supplemental Nutrition Assistance Program (SNAP) Participation Leads to Modest Changes in Diet Quality. Washington, DC: U.S. Department of Agriculture.

54. Yen S, Andrews M, Chen Z et al. (2008) Food stamp program participation and food insecurity: an instrumental variables approach. Am J Agric Econ 90, 117-132.

55. Economic Research Service (2015) State SNAP Policy Database. www.ers.usda.gov/data-products/snap-policydatabase.aspx (accessed March 2015).

56. Stacy B, Tiehen L \& Marquardt D (2018) Using a Policy Index to Capture Trends and Differences in State Administration of USDA's Supplemental Nutrition Assistance Program. Washington, DC: U.S. Department of Agriculture.

57. Rosenbaum D, Neuberger Z, Keith-Jennings B et al. (2021) Food Assistance in American Rescue Plan Act Will Reduce Hardship, Provide Economic Stimulus. Washington, DC: U.S. Department of Agriculture.

58. U.S. Department of Health and Human Services (2021) Fact Sheet: The American Rescue Plan: Reduces Health Care Costs, Expands Access to Insurance Coverage and Addresses Health Care Disparities. https://www.hhs.gov/ about/news/2021/03/12/fact-sheet-american-rescue-planreduces-health-care-costs-expands-access-insurance-coverage. html (accessed March 2021).

59. The Kaiser Family Foundation (2018) Medicaid Benefits: Dental Services. State Health Facts. https://www.kff.org/ medicaid/state-indicator/dental-services/ (accessed March 2021). 
60. The Kaiser Family Foundation (2018) Medicaid Benefits: Eyeglasses and Other Visual Aids. State Health Facts. https://www.kff.org/medicaid/state-indicator/eyeglasses/ (accessed March 2021).

61. Eide ER, Showalter MH \& Goldhaber DD (2010) The relation between children's health and academic achievement. Child Youth Serv Rev 32, 231-238.

62. Jackson SL, Vann WF Jr, Kotch JB et al. (2011) Impact of poor oral health on children's school attendance and performance. Am J Public Health 101, 1900-1906.

63. Chang HN \& Jordan P (2015) Mapping the Early Attendance Gap: Charting a Course for School Success. San Francisco, CA: Attendance Works.

64. Kim SY, Schwartz SJ, Perreira KM et al. (2018) Culture's influence on stressors, parental socialization, and developmental processes in the mental health of children of immigrants. Annu Rev Clin Psychol 14, 343-370.

65. Comeau J \& Boyle MH (2018) Patterns of poverty exposure and children's trajectories of externalizing and internalizing behaviors. SSM Popul Health 4, 86-94.
66. Gaines-Turner T, Simmons JC \& Chilton M (2019) Recommendations from SNAP participants to improve wages and end stigma. Am J Public Health 109, 1664-1667.

67. Bartfeld JS, Berger LM \& Men F (2020) Universal access to free school meals through the community eligibility provision is associated with better attendance for low-income elementary school students in Wisconsin. J Acad Nutr Diet 120, 210-218.

68. Schwartz AE \& Rothbart MW (2020) Let them eat lunch: the impact of universal free meals on school meal participation, obesity and academic achievement. J Policy Anal Manag 39, 376-410.

69. Hoynes HW, Miller DL \& Simon D (2011) Income, the earned income tax credit, and infant health. Am Econ JEcon Policy 7 , $172-211$.

70. Hamad R, Collin DF \& Rehkopf DH (2018) Estimating the short-term effects of the earned income tax credit on child health. Am J Epidemiol 2015, 1-9.

71. Gundersen CG, Hake M, Dewey A et al. (2021) Food insecurity during COVID-19. Appl Econ Perspect Policy 43, 153-161. 